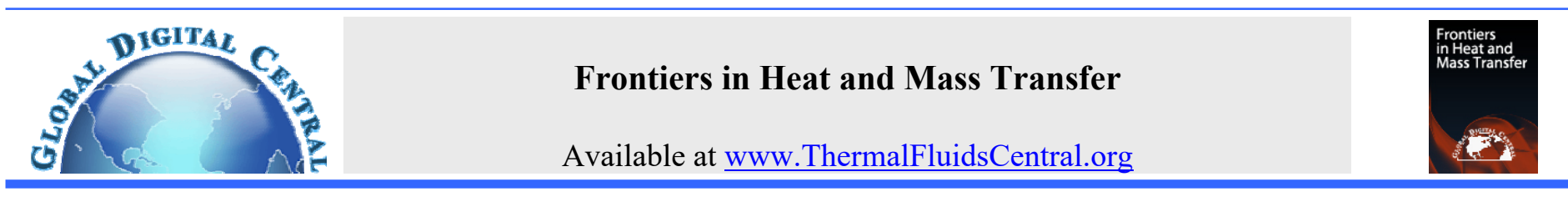

\title{
COMPUTATIONAL INVESTIGATION OF CONJUGATE HEAT TRANSFER IN CAVITY FILLED WITH SATURATED POROUS MEDIA
}

\author{
Ammar Abdulkadhim $^{\mathrm{a}}$, Azher Mouhsen Abed ${ }^{\mathrm{a}}$, Khaled Al-Farhany ${ }^{\mathrm{b}}$ \\ ${ }^{a}$ Air conditioning and Refrigeration Techniques Engineering Department, Al-Mustaqbal University College, Babylon, 51001, Iraq \\ ${ }^{\mathrm{b}}$ Department of mechanical engineering, University of Al-Qadisiyah, Al-Qadisiyah,58001, Iraq
}

\begin{abstract}
The conjugate natural convection heat transfer in a partially heated porous enclosure had been studied numerically. The governing dimensionless equations are solved using finite element method. Classical Darcy model have been used and the considering dimensionless parameters are modified Rayleigh number $\left(10 \leq \mathrm{Ra} \leq 10^{3}\right)$, finite wall thickness $(0.02 \leq \mathrm{D} \leq 0.5)$, thermal conductivity ratio $\left(0.1 \leq \mathrm{K}_{\mathrm{r}} \leq 10\right)$, and the aspect ratio $(0.5 \leq \mathrm{A} \leq 10)$. The results are presented in terms of streamlines, isotherms and local and average Nusselt number. The results indicate that heat transfer can be enhanced by increasing the modified Rayleigh number, and thermal conductivity ratio. Wall thickness effects on the heat transfer mechanism had been studied and it is found that; as the Wall thickness increases, the conduction heat transfer mechanism will be dominated. Also, increasing aspect ratio will increase the stream function and reduced the heat transfer rate.
\end{abstract}

Keywords: partially heated, conjugate, porous cavity, aspect ratio, finite element method.

\section{INTRODUCTION}

Due to the numerous engineering applications of natural convection heat transfer, a lot of investigation had been presented by many researchers. The industrial applications of natural convective fluid flow can be included in cooling storage, thermal solar-collectors, metals melting process, heat exchangers, chemical process and thermal insulation design (Basak, Singh, and Anandalakshmi 2014). Several studies regarding natural convection fluid flow in enclosure filled with pure fluid had been accomplished by (de Vahl Davis 1983; Mahapatra, Manna, and Ghosh 2015; Cianfrini et al. 2013; Kuhn and Oosthuizen 1987; Valencia and Frederick 1989; Ho and Chang 1994; Türkoglu and Yücel 1995; Alam et al. 2012). Mahapatra, Manna, and Ghosh (2015) identified numerically the optimum location of partially active wall for better heat transfer. A dimensionless correlation for heat transfer had been proposed for laminar natural convection in a rectangular enclosure filled by air (Cianfrini et al. 2013). Effect of aspect ratio had been examined numerically and experimentally in enclosure with four two-dimensional discrete heaters. A correlation for average number had been proposed in terms of modified Rayleigh number and aspect ratio had been reported by Ho and Chang (1994).

On the other hand, conjugate heat transfer in enclosures had been taken a lot of interest. Some of these studies presented by (Kaminski and Prakash 1986; Kuznetsov and Sheremet 2009; Ho and Yih 1987; Liaqat and Baytas 2001; Kahveci and Öztuna 2009; Turkoglu and Yücel 1996; Antar 2010; Cuckovic-Dzodzo, Dzodzo, and Pavlovic 1999; Antar and Baig 2009; Sambou et al. 2008). Kuznetsov and Sheremet (2009) studied numerically the heat transfer mechanism by convective-radiation with finite thickness wall heating at the bottom of the enclosure. The importance for the conjugate analysis of the thickness walls and how they may be give different results from non- conjugate analysis had been studied and examined by Liaqat and Baytas (2001). Natural convection heat transfer in porous enclosure had been studied by (Nithiarasu, Seetharamu, and Sundararajan 1997; Baytas and Pop 1999; Bin Kim 2001; Pakdee and Rattanadecho 2006; Basak et al. 2006; Pourshaghaghy, Hakkaki-Fard, and Mahdavi-Nejad 2007; Sathiyamoorthy et al. 2007; Ramakrishna et al. 2013).

A generalized model for double diffusive natural convection heat transfer in porous enclosure had been proposed by Nithiarasu, Seetharamu, and Sundararajan (1997). Natural convection phenomenon had been studied numerically in an inclined porous enclosure by Baytas and Pop (1999). Rectangular enclosure partially filled with a fluidsaturated porous medium with uniform heat generation had been examined numerically by Bin Kim (2001). Conjugate natural convection heat transfer in porous enclosure had been studied by (Baytaş et al. 2001; Saeid 2008; Saeid 2007; Saleh and Hashim 2012; Saleh et al. 2011; Sheremet and Pop 2014; Ahmed et al. 2016). Baytaş et al. (2001) studied the natural convection in a square enclosure with two-finite thickness walls in the top and the bottom of the enclosure and they found that the heat transfer decreases with the increasing of the thermal conductivity ratio.

Thermal non equilibrium model had been used by (Saeid 2008; Saeid 2007) and adopted to conjugate problem. Non-uniform heat generation in a square porous enclosure with finite thickness wall had been reported by (Saleh and Hashim 2012). Ahmed et al. (2016) demonstrated numerically by finite volume method the natural convection heat transfer in a square inclined enclosure with finite wall thickness on both sides. Biswas, Manna, and Mahapatra (2016) investigated numerically sinusoidal non-uniform heating effect over uniform heating from bottom of a square enclosure which is filled with fluid-saturated porous medium and cooled from sidewalls. Datta et al. (2016) showed how the adiabatic block body effect on the entropy generation and heat transfer enhancement. Recently, many

${ }^{*}$ Corresponding author. Email: AmmarAbdulkadhim@mustaqbal-college.edu.iq 
investigations focusing on the convection heat transfer in porous media using nanofluid as working fluid (Sheikholeslami and Seyednezhad 2018; Sheikholeslami and Rokni 2018; Sheikholeslami 2018; Sheikholeslami and Shehzad 2018; Al-Farhany and Abdulkadhim 2018).

It can be noticed from the literature review and according to the best author's knowledge that there were limitations in the studies regarding partially active walls of enclosures so this is the motivation for the present work. In this way, the main objective of the present work is to describe the natural convection heat transfer in porous enclosure partially heated from the left side wall and how the finite thickness wall effect on heat transfer rate. The finite element method used to study the effect of various dimensionless parameters such as modified Rayleigh number, thermal conductivity ratio, thickness wall and the aspect ratio on the natural convection heat transfer characteristics. The results are presented in terms of streamline, isotherms, local and average Nusselt number

\section{MATHEMATICAL and COMPUTATIONAL MODEL}

\subsection{MATHEMATICAL FORMULATION}

In this paper, two-dimension natural convection on porous cavity have been studded numerically with the effect of the partially heated conduction on vertical wall as shown in Fig. 1

The governing equations are subjected according to the assumptions:

1. The flow is considered to be two-dimensional fluid flow, laminar, and steady state.

2. The enclosure walls are impermeable.

3. The porous media is homogenous and isotropic.

4. The local thermal equilibrium is applied for porous matrix and the fluid.

5. Darcy model is applied for predictions of fluid flow inside the porous medium.

6. The internal heat generation assumed to be neglected.

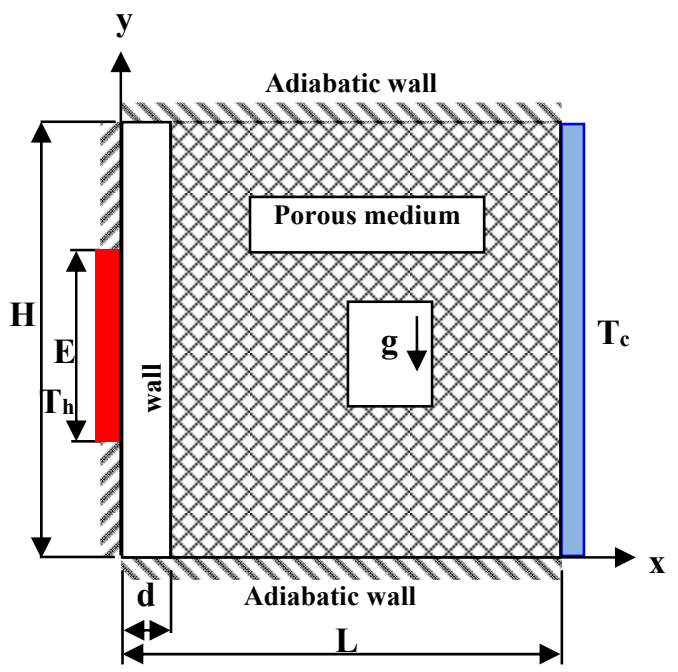

Fig. 1 Schematic diagram of the present work

The Continuity, momentum and energy of two-dimensional steady state natural convection in porous cavity equations are:

The Continuity equation is:

$\frac{\partial U}{\partial X}+\frac{\partial V}{\partial Y}=0$

$\mathrm{X}$ - and $\mathrm{Y}$ - momentum equations are :

$\frac{\partial U}{\partial Y}=-\frac{K}{\mu} \frac{\partial^{2} P}{\partial X \partial Y}$ $\frac{\partial V}{\partial X}=-\frac{\mathrm{K}}{\mu} \frac{\partial^{2} P}{\partial X \partial Y}+R a \frac{\partial T}{\partial X}$

The energy equation for porous cavity is :

$U \cdot \frac{\partial T}{\partial X}+V \cdot \frac{\partial T}{\partial Y}=\frac{\partial^{2} T}{\partial X^{2}}+\frac{\partial^{2} T}{\partial Y^{2}}$

Energy equation at the wall:

$\frac{\partial^{2} T_{W}}{\partial X^{2}}+\frac{\partial^{2} T_{W}}{\partial Y^{2}}=0$

The heat transfer at the walls are defined as in the following:

$\left.N u=\frac{1}{A} \int_{0}^{A}-\frac{\partial T}{\partial X}\right) \cdot \partial Y$

The non-dimensional parameters are:

$$
\begin{aligned}
& A=\frac{H}{L}, \quad, X=\frac{X}{L} \quad Y=\frac{y}{L}, \quad D=\frac{d}{L}, \\
& U=\frac{u L}{\alpha}, \quad V=\frac{v L}{\alpha}, \quad P=\frac{p L^{2}}{\rho \alpha^{2}}, \quad T=\frac{\bar{T}-\overline{T_{c}}}{\overline{T_{h}}-\overline{T_{c}}} \\
& \left.R a=\frac{g \beta_{T} \Delta T K L}{v \alpha}, \quad k_{r}=\frac{k_{w}}{k_{f}}\right)\left(7 k_{e f f}=\varepsilon k_{f}+(1-\varepsilon) k_{s}\right.
\end{aligned}
$$

Equations (1)-(6) are solved using non-dimensional initial boundary conditions:

$$
\begin{array}{rll}
\text { at } X=D & U=V=0 & \frac{\partial T_{w}}{\partial X}=k_{r} \frac{\partial T}{\partial X} \\
\text { at } X=1 & U=V=0 & T_{c}=0 \\
\text { at } X=0 & T_{h}=1 & \\
\text { at } Y=0, A & U=V=0 \frac{\partial T}{\partial Y}=0
\end{array}
$$

\subsection{COMPUTATIONAL MODEL}

In order to solve the problem with high accuracy and low computation time, different mesh had been tested for the minimum number of elements that leads to grid-independent solution. Fig. 2 illustrates the relation between the average Nusselt number and the resulting number of elements for square porous enclosure for all cases these tested at $\left[\mathrm{Ra}=1000, \mathrm{Da}=10^{-3}, \mathrm{D}=0.1, \mathrm{Kr}=1\right]$. It is shown that there is no effect on the average Nusselt number when the number of elements about (80000).
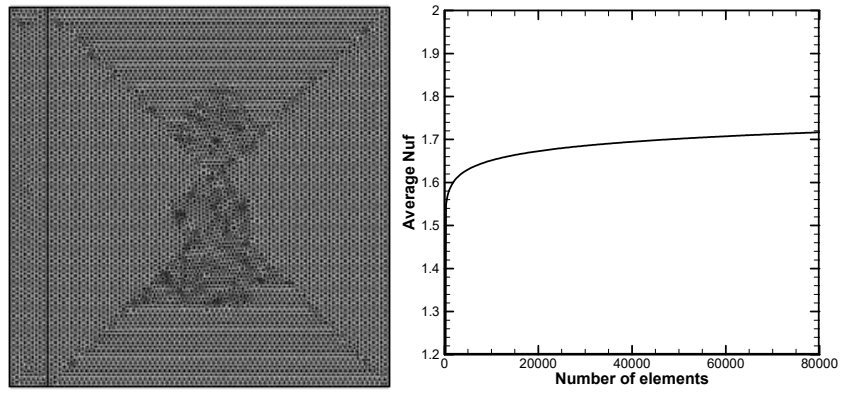

Fig. 2 Two dimensional computational domain within the triangle meshes type (left), the mesh independent study of average Nusselt number (right). 
The program had been validated regarding average Nusselt number with significant researcher as shown in Table 1. Moreover, for streamlines and isotherms contours, good agreements had been achieved with Saeid (2007) works as shown in Fig. 3.

Table-1: the validation of the present work with significant researchers

\begin{tabular}{|l|l|l|}
\hline \multirow{2}{*}{ Author average Nusselt number } & \multicolumn{2}{|c|}{ average Nusselt number } \\
\cline { 2 - 3 } & \multicolumn{1}{|c|}{$R a=10$} & $R a=100$ \\
\hline (Moya, Ramos, and Sen 1987) & 1.065 & 2.801 \\
\hline $\begin{array}{l}\text { (Beckermann, Viskanta, and Ramadhyani } \\
\text { 1986) }\end{array}$ & no data & 3.113 \\
\hline (Al-Farhany and Turan 2011) & 1.08 & 3.13 \\
\hline (Ahmed et al. 2016) & 1.093 & 3.01 \\
\hline Present Work & $\mathbf{1 . 0 8}$ & $\mathbf{3 . 0 2}$ \\
\hline
\end{tabular}
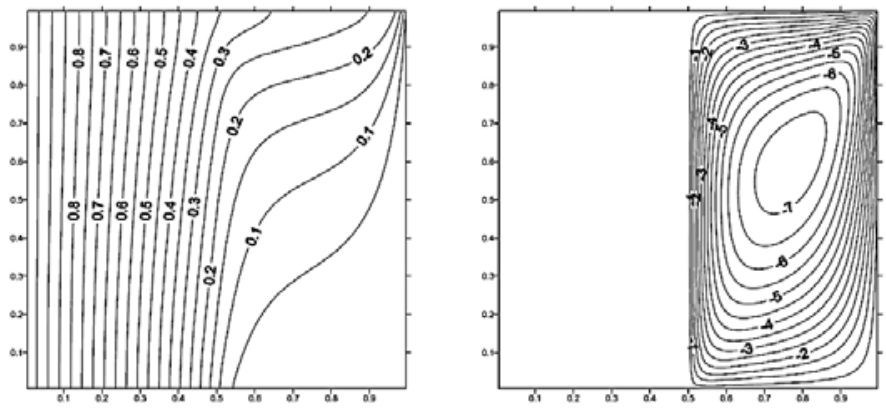

Saeid work (Saeid 2007)
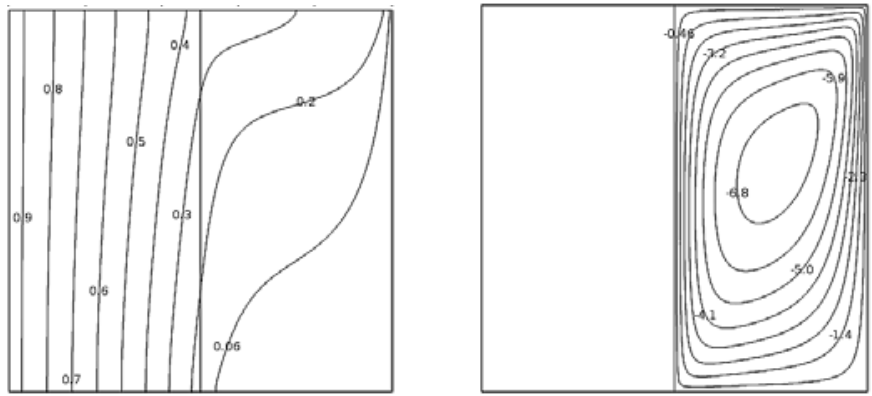

Present work

Fig. 3 Validation of the present work with Saeid work (Saeid 2007) in terms of isotherms and streamlines at $\mathrm{D}=0.1$ and 0.5 at $\mathrm{Ra}=10^{3}$.

\section{RESULTS AND DISCUSSIONS}

The results of the present work will be displayed considering the effect of the dimensionless parameters like modified Rayleigh number, finite wall thickness, thermal conductivity ratio and the aspect ratio. The results will be presented in terms of streamlines, isotherms, local and average Nusselt number for square enclosure filled with saturated porous medium.

\subsection{MODIFIED RAYLEIGH NUMBER}

Fig. 4 Demonstrates the isotherms (left) and streamlines (right) for various modified Rayleigh number and $\left[\mathrm{D}=0.1, \mathrm{~K}_{\mathrm{r}}=1\right.$, and $\left.\mathrm{E}=0.5\right]$. It can be noted that when modified Rayleigh number increase, the Nusselt number increase. This is recognized when modified Rayleigh number increase from $\mathrm{Ra}=10$ to $\mathrm{Ra}=1000, \psi_{\max }=0.56$ to $\psi_{\max }=9.79$. For example, Average Nusselt number increases from
$\overline{N u_{f}}=0.94847, \overline{N u_{w}}=1.6263$ at $\mathrm{Ra}=100$ to $\overline{N u_{f}}=3.4729$, $\overline{N u_{w}}=6.2693$ at $\mathrm{Ra}=1000$. The reason is due to increase flow circulation intensity when modified Rayleigh number increases. With respect to isotherms, it can be seen that when modified Rayleigh number $\mathrm{Ra}=10$, the isotherms have a uniform shape. This is due to weak effect of convective flow and in this case the conductive heat transfer is dominant. But, when modified Rayleigh number increases to $\mathrm{Ra}=1000$, the isotherms change their shapes obviously due to strong effect of convection heat transfer. Fig. 5 illustrates the profile of local Nusselt number for both the fluid (a) and the solid phase (b) for various values of modified Rayleigh number. As expected, the heat transfer rate enhanced significantly when $\mathrm{Ra}$ increases from 10 to $\mathrm{Ra}=1000$ due to the increasing of buoyancy and natural convection flow within the enclosure.
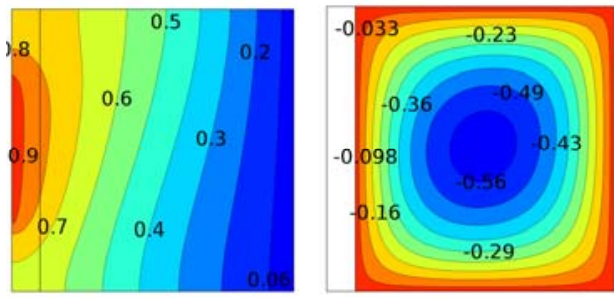

(a) $R a_{m}=10, \overline{N u_{f}}=0.94847, \overline{N u_{w}}=1.6263$
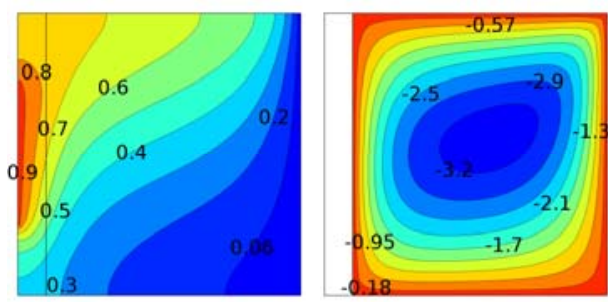

(b) $R a_{m}=100, \overline{N u_{f}}=1.8192, \overline{N u_{w}}=3.1815$
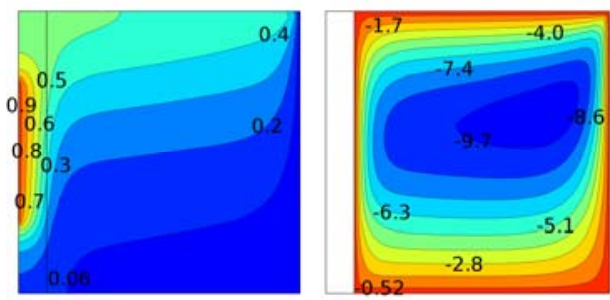

(c) $R a_{m}=1000, \overline{N u_{f}}=3,4729, \overline{N u_{w}}=6.2693$

Fig. 4 Isotherm (left) and streamlines (right) for various modified Ra number, $\mathrm{D}=0.1, \mathrm{~K}_{\mathrm{r}}=1$, and $\mathrm{E}=0.5$

\subsection{DIMENSIONLESS WALL THICKNESS EFFECT}

Fig. 6 illustrates the isotherms (left) and streamlines (right) for various dimensionless wall thickness and $\left[\mathrm{Ra}=1000, \mathrm{~K}_{\mathrm{r}}=1\right]$. It may be noted that as the dimensionless wall thickness increases, the maximum stream function will decreases. For example, when the dimensionless wall thickness increases from $\mathrm{D}=0.02$ to $\mathrm{D}=0.5, \psi_{\max }=15$ into $\psi_{\max }=6.4$. Also, the Nusselt number will decrease because the conduction heat transfer is dominant with increasing wall thickness. For example, $\overline{N u_{f}}=6.3921, \overline{N u_{w}}=12.973$ at $\mathrm{D}=0.02$ while $\overline{N u_{f}}=1.2478$, $\overline{N u_{w}}=2.153$ at $\mathrm{D}=0.5$. For the isotherms contours, it can be noticed that as the walls thickness increases, the isotherms pattern becomes more uniform which indicating that the effect of the conduction heat transfer mode becomes more significant. Moreover, the isotherms pattern shows that the heat is transferred from the left sidewall at the middle where the hot wall exists towards the cold right sidewall due to 
the large temperature gradient and this result matches with the problem boundary conditions.

Fig. 7 displays effect of dimensionless wall thickness on the local Nusselt number for the fluid phase (a) and solid phase (b). It can be noted that conduction mode will be dominant as the wall thickness increasing which leads to reducing the rate of heat transfer on the enclosure.
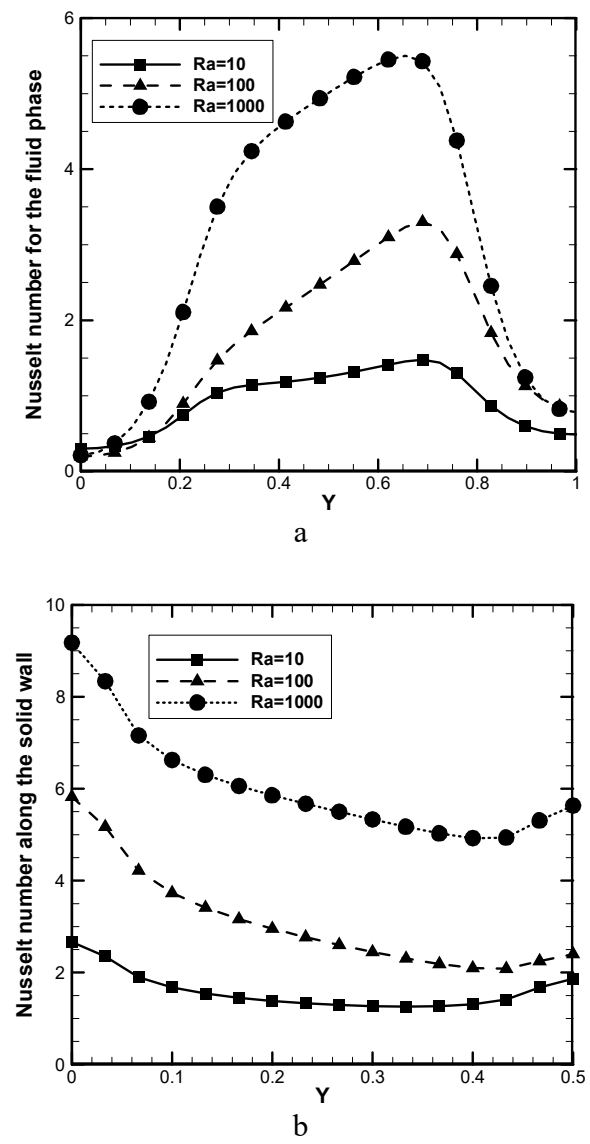

Fig. 5 Profile of local Nusselt number for (a) the fluid phase and (b) along the active hot wall for various modified Rayleigh number
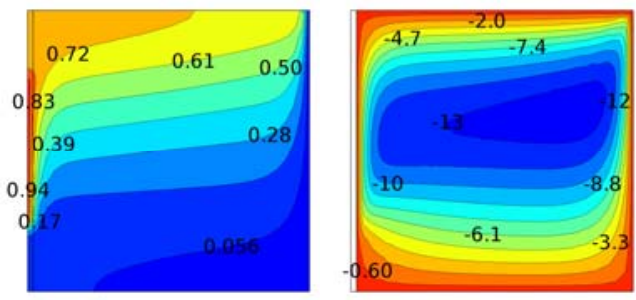

(a) $D=0.02, \overline{N u_{f}}=6.3921, \overline{N u_{w}}=12.973$
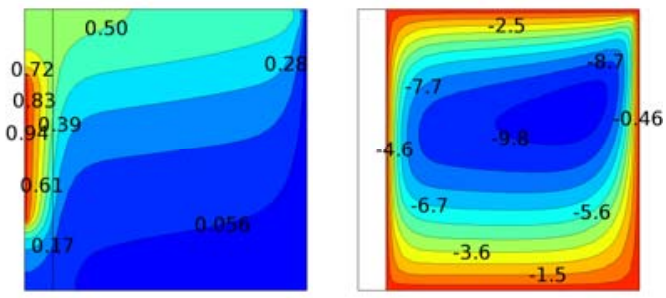

(b) $D=0.1, \overline{N u_{f}}=3.4729, \overline{N u_{w}}=6.2693$
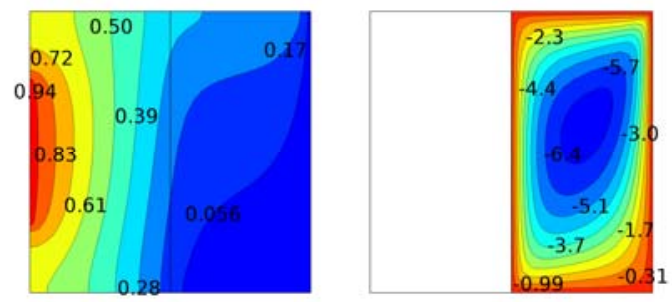

(c) $D=0.5, \overline{N u_{f}}=1.2478, \overline{N u_{w}}=2.153$

Fig. 6 Isotherm (left) and streamlines (right) for various dimensionless wall thickness, $\mathrm{Ra}=1000, \mathrm{~K}_{\mathrm{r}}=1, \mathrm{E}=0.5$

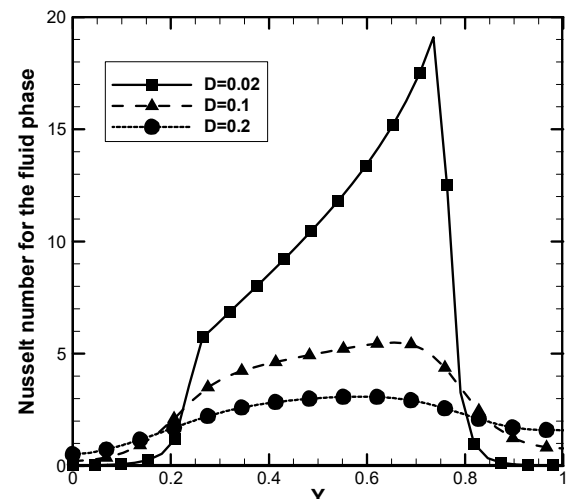

$\mathrm{a}$

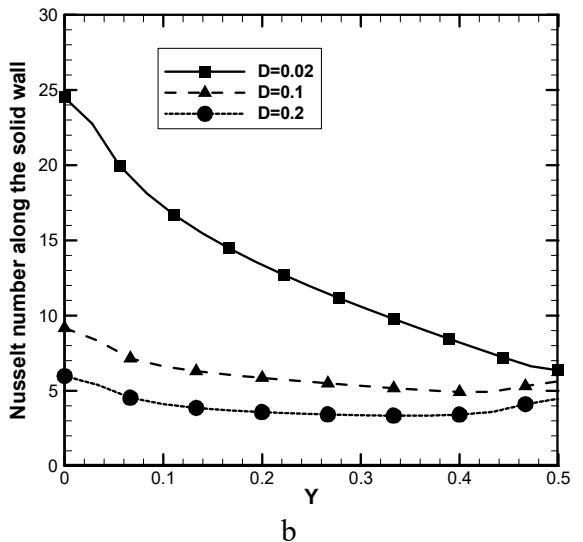

Fig. 7 Profile of local Nusselt number for the fluid phase and along the active hot wall for various finite wall thicknesses

\subsection{THERMAL CONDUCTIVITY RATIO EFFECT}

Fig. 8 displays the isotherms (left) and streamlines (right) for various thermal conductivity ratio and $[\mathrm{Ra}=1000, \mathrm{D}=0.1]$. It is known that the thermal conductivity ratio $K_{\mathrm{r}}$ is defined as the ratio of the thermal conductivity of solid walls to the thermal conductivity of the fluid. Therefore, from this definition it can be obtained that when the thermal conductivity ratio $K_{\mathrm{r}}$ is small, i.e., $K_{\mathrm{r}}=1$, the thermal conductivity of walls is small, too. So, the thermal resistance is high and as a result the average Nusselt number at solid walls is high, while the average Nusselt number of fluids is low. On the contrary, when the thermal conductivity ratio increases from $K_{\mathrm{r}}=1$ to $K_{\mathrm{r}}=10$, the thermal conductivity of solid walls increases, i.e., convection decreases, while it decreases for the fluid, i.e., convection increases. For example, when thermal conductivity ratio increases from $K_{r}=1$ to $K_{r}=10$, maximum stream function value will increases from $\psi_{\text {max }}=9.7$ to $\psi_{\text {max }}=15$ respectively. For this reason, the average Nusselt number at solid walls decreases from $\overline{N u_{w}}=6.3712$ at $\mathrm{K}_{\mathrm{r}}=1$ to $\overline{N u_{w}}=1.7256$ at $\mathrm{K}_{\mathrm{r}}=10$. On the other hand, average Nusselt number for the fluid phase increases 
from $\overline{N u_{f}}=3.3715$ at $\mathrm{K}_{\mathrm{r}}=1$ to $\overline{N u_{f}}=9.9799$ at $\mathrm{K}_{\mathrm{r}}=10$. This result demonstrates that the heat transfer mechanism inside the enclosure is converted from conduction mode when $\mathrm{K}_{\mathrm{r}}$ is small into convection mode when $K_{r}$ is high. Fig.9 illustrates the effect of thermal conductivity ratio for the fluid phase (a) and along the sold wall (b). the results indicates that when the thermal conductivity ratio increases, the thermal conductivity of the fluid phase decreases. This leads to enhancing of the natural convection heat transfer and increasing the local Nusselt number for the fluid phase. However this behavior is completely reversed for the Nusselt number along the solid wall. Actually, the local Nusselt number along the hot wall decreases as the thermal conductivity ratio increases which leads to enhancing in the conduction effect.
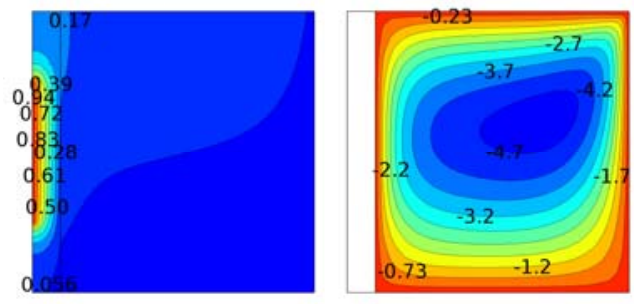

(a) $K_{r}=0.1, \overline{N u_{f}}=2.8531, \overline{N u_{w}}=9.4808$
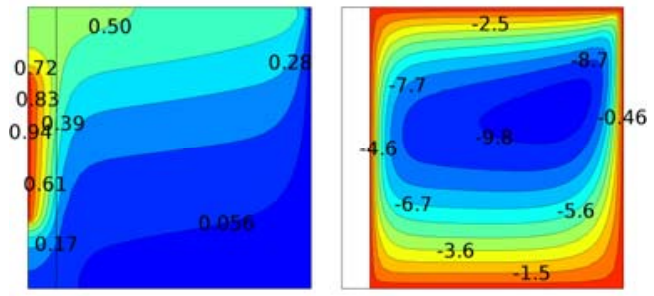

(b) $K_{r}=1, \overline{N u_{f}}=3.3715, \overline{N u_{w}}=6.3712$
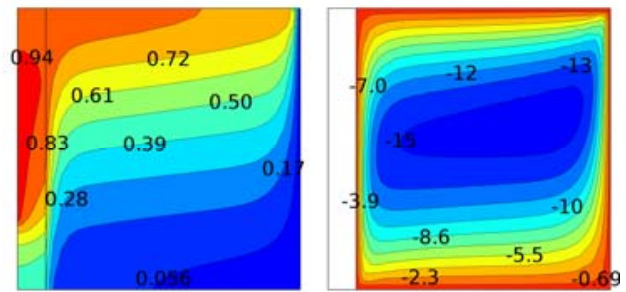

(c) $K_{r}=10, \overline{N u_{f}}=4.9799, \overline{N u_{w}}=1.7256$

Fig. 8 Isotherm (left) and streamlines (right) for various thermal conductivity ratio, $\mathrm{Ra}=1000, \mathrm{D}=0.1, \mathrm{E}=0.5$

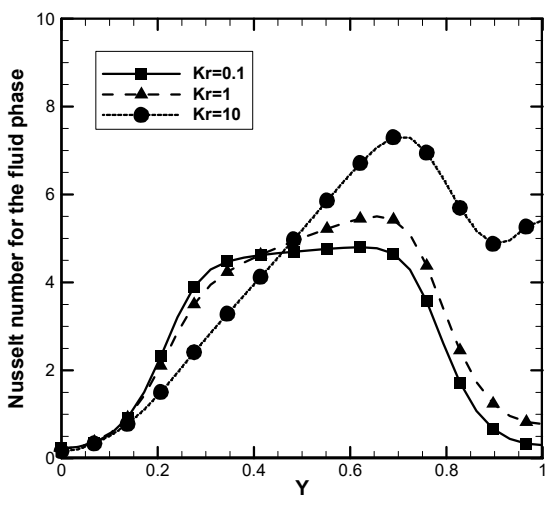

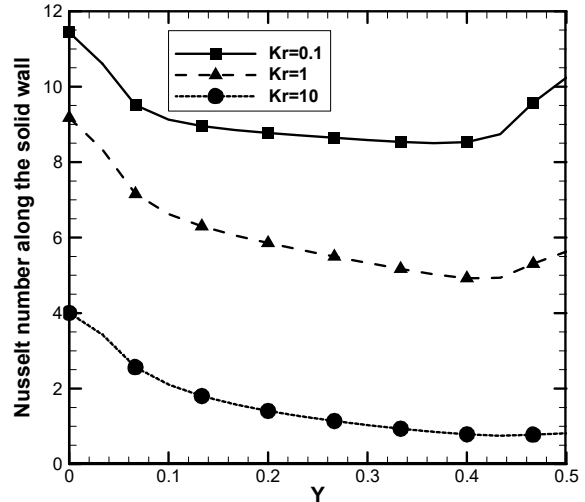

$\mathrm{b}$

Fig. 9 Profile of local Nusselt number for the fluid phase and along the active hot wall for various thermal conductivity ratios.

\subsection{EFFECT OF ASPECT RATIO}

The effect of aspect ratio on heat transfer rate is presented in Fig. 10. It can benoted that as the aspct ratio increases, stream function value increases. For example $\psi_{\max }=6.3$ at aspect ratio equals to 0.5 while it increases to $\psi_{\max }=41$ at aspect ratio $=10$. Fig. 11 illustrates the effect of aspect ratio on average Nusselt number for various modified Rayleigh numbers. At low Rayleigh numbers $(\mathrm{Ra}<100)$ when the aspect ratio increases from 0.5 to 1 , the average Nusselt number decreses. After that it increases again till aspect ratio increases to 2 . After that increasing aspect ratio will lead to decrease in the heat transfer rate. But, at high modified Rayleigh number, when the aspect ratio increases from 0.5 to 1 , the Nusselt number will increases. Beyond that, increasing aspect ratio will lead to contioneous reducing in the heat transfe rate.

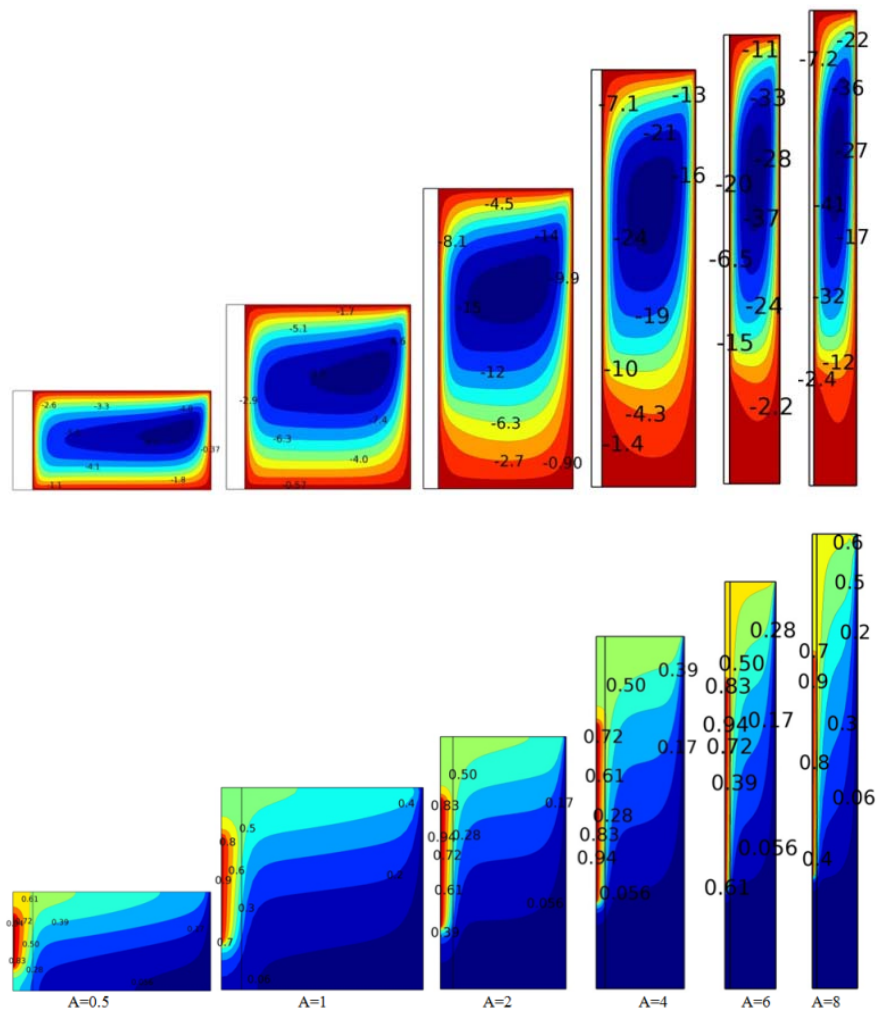

Fig. 10 Streamlines (Top) and isotherms (bottom) for various aspect ratio at $\mathrm{D}=0.1, \mathrm{Ra}=10^{3}$. 


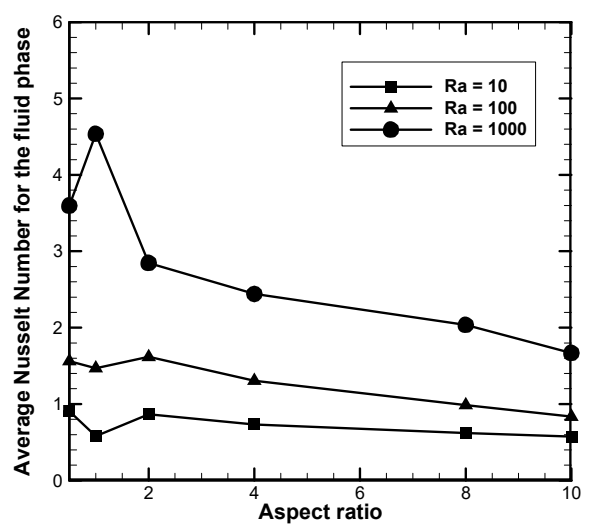

Fig. 11 Profile of average Nusselt number for the fluid phase with aspect ratio for various modified Rayleigh number.

\section{CONCLUSIONS}

The present work illustrates numerically the natural convection heat transfer in enclosure filled with porous media using Darcy model. The results can be summarized as follow:

1. When the dimensionless wall thickness increases, the convection mechanism will be converted into conduction mode. This will reduce the Nusselt number leading to reduce the rate of heat transfer.

2. When the thermal conductivity ratio increases, the local Nusselt number for the fluid phase will increase. While a reverse behavior for local Nusselt number along the heated wall.

3. As the Rayleigh number increases, the heat transfer rate will be enhanced, as a results, local Nusselt number for both fluid and solid phase will be increased.

4. Increasing of the aspect ratio makes the flow strength increases and the heat transfer decreases.

\section{NOMENCLATURE}

A aspect ratio

d dimensional wall thickness $\mathrm{m}^{-1}$

D non-dimensional wall thickness

Da Darcy number

g gravitational acceleration, $\mathrm{m} \mathrm{s}^{-2}$

$\mathrm{H}$ high of the enclosure, $\mathrm{m}$

$\mathrm{K}$

$\mathrm{k}$

$\mathrm{k}_{\mathrm{r}}$

L

$\mathrm{Nu}$

$\mathrm{p}$

$\mathrm{P}$

$\operatorname{Pr}$

$\mathrm{Ra}$

$\mathrm{t}$

$\mathrm{T}$

$\bar{T}$

$\mathrm{u}$

$\mathrm{v}$

$\mathrm{x}$

y

U

V

$\mathrm{X}$

Y

permeability of the porous medium, $\mathrm{m}^{2}$

thermal conductivity, $\mathrm{W} \mathrm{m}^{-1} \mathrm{~K}^{-1}$

thermal conductivity ratio, $\mathrm{k}_{\mathrm{r}}=\mathrm{k}_{\mathrm{w}} / \mathrm{k}_{\mathrm{f}}$

length of the enclosure, $m$

Nusselt number

pressure, $\mathrm{kg} \mathrm{m}^{-1} \mathrm{~s}^{-2}$

non-dimensional pressure,

Prandtl number,

modified Rayleigh number for porous medium,

time, $s$

non-dimensional temperature,

dimensional temperature, $\mathrm{K}$

velocity components in $\mathrm{x}$-direction, $\mathrm{m} \mathrm{s}^{-1}$

velocity components in y-direction, $\mathrm{m} \mathrm{s}^{-1}$

$\mathrm{x}$ coordinates, $\mathrm{m}$

$\mathrm{y}$ coordinates, $\mathrm{m}$

non-dimensional velocity components in $\mathrm{X}$-direction,

non-dimensional velocity components in $\mathrm{Y}$-direction,

non-dimensional X-coordinates,

non-dimensional Y-coordinates,

Greek symbols

$\alpha \quad$ effective thermal diffusivity, $\mathrm{m}^{2} \mathrm{~s}^{-1}$
$\beta_{\mathrm{T}} \quad$ coefficient of thermal expansion, $\mathrm{K}^{-1}$

$v \quad$ kinematic viscosity, $\mathrm{m}^{2} \mathrm{~s}^{-1}$

$\rho \quad$ density, $\mathrm{kg} \mathrm{m}^{-3}$

Subscripts

c cold

eff effective

f fluid

h hot

w wall

\section{REFERENCES}

Ahmed, Sameh Elsayed, Ahmed Hussein, MM Abd El-Aziz, and Sivanandam Sivasankaran. 2016, "Conjugate natural convection in an inclined square porous enclosure with finite wall thickness and partially heated from its left sidewall," Heat Transfer Research, 47, 383-402 http://dx.doi.org/10.1615/HeatTransRes.2016007964

Al-Farhany, K., and Ammar Abdulkadhim. 2018, "Numerical investigation of conjugate natural convection heat transfer in a square porous cavity heated partially from left sidewall," INTERNATIONAL JOURNAL OF HEAT AND TECHNOLOGY, 36 , 237-244. http://dx.doi.org/10.18280/ijht.360132

Al-Farhany, K., and A. Turan. 2011, "Unsteady Conjugate Natural Convective Heat Transfer in a Saturated Porous Square Domain Generalized Model," Numerical Heat Transfer, Part A: Applications, 60, 746-65. https://doi.org/10.1080/10407782.2011.627793

Alam, Pravez, Ashok Kumar, S Kapoor, and SR Ansari. 2012, "Numerical investigation of natural convection in a rectangular enclosure due to partial heating and cooling at vertical walls," Communications in Nonlinear Science and Numerical Simulation, 17, 2403-14.

https://doi.org/10.1016/j.cnsns.2011.09.004

Antar, Mohamed A. 2010, "Thermal radiation role in conjugate heat transfer across a multiple-cavity building block," Energy, 35, 3508-16. https://doi.org/10.1016/j.energy.2010.04.055

Antar, Mohamed A, and Hasan Baig. 2009, "Conjugate conduction-natural convection heat transfer in a hollow building block," Applied Thermal Engineering,29,3716-2037.

https://doi.org/10.1016/j.applthermaleng.2009.04.033

Basak, Tanmay, S Roy, T Paul, and I Pop. 2006, "Natural convection in a square cavity filled with a porous medium: effects of various thermal boundary conditions," International Journal of Heat and Mass Transfer,49,1430-41. https://doi.org/10.1016/j.ijheatmasstransfer.2005.09.018

Basak, Tanmay, Abhishek Kumar Singh, and R Anandalakshmi. 2014, “Analysis of entropy generation during conjugate natural convection within a square cavity with various location of wall thickness," Industrial \& EngineeringChemistryResearch,53:3702-22. http://dx.doi.org/10.1021/ie403033f

Baytas, A C, and I Pop. 1999, "Free convection in oblique enclosures filled with a porous medium," International Journal of Heat and Mass Transfer, 42, 104757. https://doi.org/10.1016/S0017-9310(98)00208-7

Baytaş, AC, A Liaqat, T Groșan, and I Pop. 2001, "Conjugate natural convection in a square porous cavity," Heat and Mass Transfer, 37, 467-73. https://doi.org/10.1007/PL00013297

Beckermann, C, R Viskanta, and S Ramadhyani. 1986, “A numerical study of non-Darcian natural convection in a vertical enclosure filled with a porous medium," Numerical Heat Transfer, 10, 557-70.

https://doi.org/10.1080/10407788608913535

Bin Kim, Jae Min Hyun, Ho Sang Kwak, Gi. 2001, "Buoyant convection in a square cavity partially filled with a heat-generating porous medium," Numerical Heat Transfer: Part A: Applications, 40, 601-18. https://doi.org/10.1080/10407780152655388

Biswas, Nirmalendu, Nirmal K Manna, and Pallab Sinha Mahapatra. 2016, "Merit of non-uniform over uniform heating in a porous cavity," International Communications in Heat and Mass Transfer, 78, 135-44. 


\section{https://doi.org/10.1016/j.icheatmasstransfer.2016.09.001}

Cianfrini, C, M Corcione, E Habib, and A Quintino. 2013, "Convective transport in rectangular cavities partially heated at the bottom and cooled at one side," Journal of Thermal Science, 22, 55-63. https://doi.org/10.1007/s11630-013$\underline{0592-3}$

Cuckovic-Dzodzo, DM, MB Dzodzo, and MD Pavlovic. 1999, "Laminar natural convection in a fully partitioned enclosure containing fluid with nonlinear thermophysical properties," International journal of heat and fluid flow, 20, 61423.

https://doi.org/10.1016/S0142-727X(99)00053-3

Datta, Priyankan, Pallab Sinha Mahapatra, Koushik Ghosh, Nirmal K Manna, and Swarnendu Sen. 2016, "Heat transfer and entropy generation in a porous square enclosure in presence of an adiabatic block," Transport in Porous Media, 111, 305-29. https://doi.org/10.1007/s11242-015-0595-5

de Vahl Davis, G. 1983, "Natural convection of air in a square cavity: a bench mark numerical solution," International Journal for numerical methods in fluids, 3, 249-64.

https://doi.org/10.1002/fld.1650030305

Ho, CJ, and JY Chang. 1994, "A study of natural convection heat transfer in a vertical rectangular enclosure with two-dimensional discrete heating: effect of aspect ratio," International Journal of Heat and Mass Transfer, 37, 917-25.

https://doi.org/10.1002/fld.1650030305

Ho, CJ, and YL Yih. 1987, "Conjugate natural convection heat transfer in an airfilled rectangular cavity," International Communications in Heat and Mass Transfer, 14: 91-100. https://doi.org/10.1016/0735-1933(87)90011-X

Kahveci, Kamil, and Semiha Öztuna. 2009, "MHD natural convection flow and heat transfer in a laterally heated partitioned enclosure," European Journal of Mechanics-B/Fluids,28,744-52. https://doi.org/10.1016/j.euromechflu.2009.07.001

Kaminski, DA, and C Prakash. 1986, "Conjugate natural convection in a square enclosure: effect of conduction in one of the vertical walls," International Journal of Heat and Mass Transfer, 29, 1979-88. https://doi.org/10.1016/0017$\underline{9310(86) 90017-7}$

Kuhn, D, and PH Oosthuizen. 1987, "Unsteady natural convection in a partially heated rectangular cavity," Journal of Heat Transfer (Transactions of the ASME (American Society of Mechanical Engineers), Series C);(United States), 109, 798-801

http://dx.doi.org/10.1115/1.3248163

Kuznetsov, Geniy Vladimirovich, and Mikhail Alexandrovich Sheremet. 2009, "Conjugate natural convection with radiation in an enclosure," International Journal of Heat and Mass Transfer, 52: 2215-2223. https://doi.org/10.1016/j.ijheatmasstransfer.2008.12.006

Liaqat, A, and AC Baytas. 2001, "Conjugate natural convection in a square enclosure containing volumetric sources," International Journal of Heat and Mass Transfer, 44: 3273-3280. https://doi.org/10.1016/S0017-9310(00)00345-8

Mahapatra, Pallab Sinha, Nirmal K Manna, and Koushik Ghosh. 2015, "Effect of active wall location in a partially heated enclosure," International Communications in Heat and Mass Transfer, 61: 69-77. https://doi.org/10.1016/j.icheatmasstransfer.2014.12.019

Moya, Sara L, Eduardo Ramos, and Mihir Sen. 1987, "Numerical study of natural convection in a tilted rectangular porous material," International Journal of Heat and Mass Transfer, 30: 741-756. https://doi.org/10.1016/00179310(87)90204-3

Nithiarasu, P, KN Seetharamu, and T Sundararajan. 1997, "Non-Darcy doublediffusive natural convection in axisymmetric fluid saturated porous cavitiesNicht-Darcysche Doppeldiffusion bei natürlicher Konvektion in achsialsymmetrischen, fluidgetränkten porösen Ringräumen," Heat and Mass Transfer, 32: 427-433. https://doi.org/10.1007/s002310050141

Pakdee, Watit, and Phadungsak Rattanadecho. 2006. "Natural convection in porous enclosure caused by partial heating or cooling." In The 20th Conference of Mechanical Engineering Network of Thailand, 18-20.
Pourshaghaghy, A, A Hakkaki-Fard, and A Mahdavi-Nejad. 2007, "Direct simulation of natural convection in square porous enclosure," Energy Conversion and Management, 48: 1579-1589. https://doi.org/10.1016/j.enconman.2006.11.013

Ramakrishna, D, Tanmay Basak, S Roy, and I Pop. 2013, “Analysis of heatlines during natural convection within porous square enclosures: effects of thermal aspect ratio and thermal boundary conditions," International Journal of Heat and Mass Transfer, 59: 206-218.

https://doi.org/10.1016/j.ijheatmasstransfer.2012.11.076

Saeid, Nawaf. 2008, "Conjugate natural convection in a porous enclosure sandwiched by finite walls under thermal nonequilibrium conditions," Journal of Porous Media, 11, 259-275. https://doi.org/10.1615/JPorMedia.v11.i3.40

Saeid, Nawaf H. 2007, "Conjugate natural convection in a porous enclosure: effect of conduction in one of the vertical walls," International Journal of Thermal Sciences, 46: 531-539.

https://doi.org/10.1016/j.ijthermalsci.2006.08.003

Saleh, H, and Ishak Hashim. 2012, "Conjugate natural convection in a porous enclosure with non-uniform heat generation," Transport in porous media, 94: 759-774. https://doi.org/10.1007/s11242-012-0023-z

Saleh, H, NH Saeid, Ishak Hashim, and Zainol Mustafa. 2011, "Effect of conduction in bottom wall on Darcy-Bénard convection in a porous enclosure," Transport in porous media, 88: 357-368. https://doi.org/10.1007/s11242-011$\underline{9743-8}$

Sambou, V, B Lartigue, F Monchoux, and M Adj. 2008, "Theoretical and experimental study of heat transfer through a vertical partitioned enclosure: application to the optimization of the thermal resistance," Applied Thermal Engineering, 28: 488-498. https://doi.org/10.1016/j.applthermaleng.2007.05.008

Sathiyamoorthy, M, Tanmay Basak, S Roy, and I Pop. 2007, "Steady natural convection flow in a square cavity filled with a porous medium for linearly heated side wall (s)," International Journal of Heat and Mass Transfer, 50: 1892-1901. https://doi.org/10.1016/j.applthermaleng.2007.05.008

Sheikholeslami, M, and Houman B Rokni. 2018, "CVFEM for effect of Lorentz forces on nanofluid flow in a porous complex shaped enclosure by means of non-equilibrium model," Journal of Molecular Liquids, 254: 446-462. https://doi.org/10.1016/j.molliq.2018.01.130

Sheikholeslami, M, and SA Shehzad. 2018, "Simulation of water based nanofluid convective flow inside a porous enclosure via non-equilibrium model," International Journal of Heat and Mass Transfer, 120: 1200-1212. https://doi.org/10.1016/j.ijheatmasstransfer.2017.12.132

Sheikholeslami, Mohsen. 2018, "CuO-water nanofluid flow due to magnetic field inside a porous media considering Brownian motion," Journal of Molecular Liquids, 249: 921-929. https://doi.org/10.1016/j.molliq.2017.11.118

Sheikholeslami, Mohsen, and Mohadeseh Seyednezhad. 2018, "Simulation of nanofluid flow and natural convection in a porous media under the influence of electric field using CVFEM," International Journal of Heat and Mass Transfer, 120: 772-781. https://doi.org/10.1016/j.ijheatmasstransfer.2017.12.087

Sheremet, Mikhail Alexandrovich, and Ioan Pop. 2014, "Conjugate natural convection in a square porous cavity filled by a nanofluid using Buongiorno's mathematical model," International Journal of Heat and Mass Transfer, 79: 137-145. https://doi.org/10.1016/j.ijheatmasstransfer.2014.07.092

Turkoglu, Hasmet, and Nuri Yücel. 1996, "Natural convection heat transfer in enclosures with conducting multiple partitions and side wallsWärmeübergang bei natürlicher Konvektion in Kammern mit wärmeleitenden Mehrfachtrenn-und Seitenwänden," Heat and Mass Transfer, 32: 1-8. https://doi.org/10.1007/s002310050084

Türkoglu, Hasmet, and Nuri Yücel. 1995, "Effect of heater and cooler locations on natural convection in square cavities," Numerical Heat Transfer, Part A: Applications, 27: 351-358. https://doi.org/10.1080/10407789508913705

Valencia, Alvaro, and Ramón L Frederick. 1989, "Heat transfer in square cavities with partially active vertical walls," International Journal of Heat and Mass Transfer, 32: 1567-1574. https://doi.org/10.1016/0017-9310(89)90078-1 